\title{
Solution Properties of Poly(vinylpyrrolidone) in Cosolvent Systems
}

\author{
Abdel-Azim A. Abdel-Azim, ${ }^{*}{ }^{\dagger}$ Heikki Tenhu, ${ }^{* *}$ Juha Merta, ${ }^{* *}$ \\ and Franciska SunDHOLM** \\ * Egyptian Petroleum Research Institute, Nasr City, Cairo, Egypt \\ ** Department of Polymer Chemistry, University of Helsinki, Meritullinkatu 1 \\ A, SF-00170 Helsinki, Finland
}

(Received October 1, 1992)

\begin{abstract}
For solutions of well fractionated poly(vinylpyrrolidone) (PVP) samples of different relative molar mass $M$, intrinsic viscosities $[\eta]$ have been measured at $298.15 \mathrm{~K}$ in pure water and water/acetone mixtures. Upon mixing water (good solvent) and acetone (poor solvent), thermodynamically better solvents could be obtained. The cosolvancy was detected from the viscosity measurements. Several graphical procedures have been utilized for deriving the unperturbed dimensions of PVP expressed as $K_{\theta}$ (in the relationship $[\eta]=K_{\theta} M^{1 / 2} \alpha^{3}$, where $\alpha$ is the expansion factor). It was found that the unperturbed dimensions were not constant and differed from those measured in the $\theta$-solvent (water/acetone mixture having volume fraction of acetone $\left(\phi_{\text {ACT }}\right)=0.668$ ) in which $K_{\theta}$ was found to be $74 \times 10^{-3} \mathrm{dm}^{3} \mathrm{~kg}^{-1}$. A solvent-dependent parameter has been utilized to correct the $K_{\theta}$ values derived from Stockmayer-Fixman plot, in each solvent, for the sake of achieving a constant value of $K_{\theta}$ via these plots. Values ranging between $73 \times 10^{-3}$ and $75 \times 10^{-3} \mathrm{dm}^{3} \mathrm{~kg}^{-1}$ with a mean of $74 \times 10^{-3} \mathrm{dm}^{3} \mathrm{~kg}^{-1}$ were obtained by utilizing the proposed correction, thus yielding $0.666 \AA \mathrm{g}^{-(1 / 2)} \mathrm{mol}^{1 / 2}$ for unperturbed polymer dimensions, $\left(\left\langle r^{2}\right\rangle_{0} / M\right)^{1 / 2}$.

KEY WORDS Poly(vinylpyrrolidone) / Water / Acetone / Unperturbed

Dimensions / Intrinsic Viscosity / Cosolvent Systems / Solution Properties /
\end{abstract}

In some previous communications ${ }^{1-5}$ published by the senior author of the present article, it was reported that the unperturbed dimensions (UD) of polystyrene were constant and independent of the type of the solvent used. This finding was in contrast to other data published in this respect. ${ }^{6-11}$ The same author found that the UD of polystyrene in cosolvent systems ${ }^{12}$ were not constant and differed from those in the single $\theta$-solvent.

The use of a binary liquid mixture is inevitable in cases where a suitable single solvent is not available for a polymer. Using binary liquid mixtures as solvents for a polymer introduces theoretical and experimental problems of various kinds, some of them similar to those for single solvents, and other specific of ternary systems, such as unperturbed dimension variations. ${ }^{12,13-15}$

Dondos and Benoit ${ }^{16}$ reported that unique value of $K_{\theta}$ was obtained, via Stockmayer-Fixman procedure, for a given polymer in all pure solvents. In the case of binary mixtures, they reported that the $K_{\theta}$ value was found higher or lower than this unique value depending upon the solvent-solvent interaction parameter $\chi_{12}$ characterizing the solvent mixture.

However, it seems that solvent-solvent effects on the UD are more difficult to interpret. The effect of excess free energy, $G^{\mathrm{E}}$, of the mixture on the molecular dimensions of a polymer has been studied by Dondos and Benoit. 8,17

\footnotetext{
† To whom all correspondence should be addressed.
} 
In the present report, we are concerned with poly(vinylpyrrolidone) because it is a widely applied polymer. ${ }^{18-20}$ A certain range of molecular mass of PVP is a valuable blood plasma extender. For this reason the evaluation of its molecular mass and molecular dimensions is important.

The molecular characteristics of PVP have been described in many papers. ${ }^{21-27}$ However, the reported viscosity-molecular mass relationship for PVP vary greatly. Consequently, the main aim of the present investigation was to study the effect of solvent on the unperturbed dimensions of PVP in a series of mixed solvents exhibiting a synergistic effect and to test the applicability of some extrapolation procedures for deriving the unperturbed polymer dimensions from measurements of $[\eta]$ in non-ideal solvents.

\section{EXPERIMENTAL}

\section{Materials}

Analytical grade acetone and chloroform were used after distillation at atmospheric pressure. Petroleum ether $60-80$, pure grade, was utilized as precipitant. The water employed was deionized and bidistilled. Fifteen PVP fractions prepared from PVP (K-90, K-60, and $\mathrm{K}-30)$ ) by precipitation in chloroform (solvent) and petroleum ether 60-80 (non-solvent) mixtures at $298.15 \mathrm{~K}^{27}$ The PVP fractions were designated as PVP1-PVP15 with decreasing the molecular weight. All chemicals were obtained from Fluka AG, Switzerland.

\section{Procedures}

Mixed solvents were made up volumetrically to volume fractions of acetone, $\phi_{\text {ACT }}$ at $298.15 \mathrm{~K}$ of $0.1,0.2,0.25,0.3,0.4,0.5,0.6$, and 0.668 , denoted here as solvent $\mathrm{b}, \mathrm{c}, \mathrm{d}, \mathrm{e}, \mathrm{f}, \mathrm{g}$, $\mathrm{h}$, and i, respectively. The pure solvent (water) is designated as solvent a.

Polymer solutions were prepared gravimetrically at $298.15 \mathrm{~K}$ and solution viscosity measured in an Ubbelohde dilution viscometer at the same temperature. The temperature was maintained at $298.15 \mathrm{~K}$ by using a Lauda thermostat type D40-SK with accuracy \pm $0.02 \mathrm{~K}$.

Intrinsic viscosities $[\eta]$ were obtained by treating the viscosity data of the polymer solution by double extrapolation according to Huggins $^{28}$ and Kraemer ${ }^{29}$ equations.

\section{RESULTS AND DISCUSSION}

\section{Intrinsic Viscosity}

The molar masses of the fractionated PVP samples, $M$, were determined from limiting viscosity numbers in methanol at $303.15 \mathrm{~K}$ according to Frank and Levy ${ }^{23}$ who concluded that the viscosity-average molar mass for PVP in methanolic solution at $303.15 \mathrm{~K}$ can be formulated as: $[\eta]=18 \times 10^{-3} M^{0.68}$.

It has been established ${ }^{25,30,31}$ that water/ acetone binary mixture having the volume fraction of acetone, $\phi_{\mathrm{ACT}}$, equal to 0.668 is the $\theta$-solvent for PVP at $298.15 \mathrm{~K}$. As a cross check for $M$, the intrinsic viscosity of PVP solutions in water/acetone $\left(\phi_{\mathrm{ACT}}=0.668\right)$ were measured at theta temperature viz., $298.15 \mathrm{~K}$. The molar masses of the samples were confirmed from Kuhn-Mark-Houwink-Sakurada (KMHS) and Stockmayer-Fixman ${ }^{32}$ plots, since the obtained slopes were 0.5 and zero respectively. The codes of the PVP samples and their relative molar masses are listed in Table I.

Mark-Houwink plots for all PVP samples, in pure water and eight mixed solvents, were performed according to the equation

$$
[\eta]=K_{\mathrm{m}} M^{v}
$$

The graphs are not reproduced here but the derived values of the constants $K_{\mathrm{m}}$ and $v$ are listed in Table II. The variation of $K_{\mathrm{m}}$ and $v$ with the composition of the mixed solvent expressed as $\phi_{\mathrm{ACT}}$ is illustrated in Figure 1. The obtained viscometric exponent $v$ for PVP in pure water (solvent a) is identical with the value of 0.82 given by Meza and Gargallo. ${ }^{25}$ Scholtan ${ }^{22}$ reported a value of 0.7 for $v$ in the 
Table I. Code and relative molar masses for PVP fractions

\begin{tabular}{lclr}
\hline Code & $M \times 10^{-3}$ & Code & $M \times 10^{-3}$ \\
\hline PVP1 & 512 & PVP9 & 174 \\
PVP2 & 431 & PVP10 & 151 \\
PVP3 & 410 & PVP11 & 103 \\
PVP4 & 341 & PVP12 & 62 \\
PVP5 & 291 & PVP13 & 45 \\
PVP6 & 262 & PVP14 & 32 \\
PVP7 & 243 & PVP15 & 28 \\
PVP8 & 211 & & \\
\hline
\end{tabular}

Table II. Mark-Houwink constants $K_{\mathrm{m}}$ and $v$ for PVP in pure water (solvent a) and different mixed solvents (solvents $\mathrm{b}-\mathrm{i}$ )

\begin{tabular}{|c|c|c|c|c|}
\hline \multicolumn{2}{|c|}{ Solvent } & \multirow{2}{*}{$\frac{K_{\mathrm{m}} \times 10^{3}}{\mathrm{dm}^{3} \mathrm{~kg}^{-1}}$} & \multirow{2}{*}{$v$} & \multirow{2}{*}{$\mathrm{SD} \times 10^{5}$} \\
\hline Code & $\phi_{\text {ACT }}$ & & & \\
\hline a & 0.00 & 3.90 & 0.82 & 3.2 \\
\hline b & 0.10 & 3.75 & 0.83 & 4.9 \\
\hline $\mathrm{c}$ & 0.20 & 3.15 & 0.86 & 12.6 \\
\hline $\mathrm{d}$ & 0.25 & 3.30 & 0.85 & 2.0 \\
\hline $\mathrm{e}$ & 0.30 & 3.70 & 0.83 & 71.7 \\
\hline f & 0.40 & 4.20 & 0.81 & 2.5 \\
\hline $\mathrm{g}$ & 0.50 & 8.00 & 0.73 & 2.7 \\
\hline $\mathrm{h}$ & 0.60 & 26.90 & 0.60 & 2.0 \\
\hline $\mathrm{i}$ & 0.668 & 74.00 & 0.50 & 1.0 \\
\hline
\end{tabular}

a $\mathrm{SD}=$ The standard deviation of the least-squares analysis used for obtaining KMHS constants $K_{\mathrm{m}}$ and $v$.

molar mass range $10 \times 10^{3}-200 \times 10^{3}$. He stated that when the molar mass exceeds this range, the value of $v$ decreases as the molar mass increases. The molar mass range in the present work is $28 \times 10^{3}-512 \times 10^{3}$. The relationship $[\eta]=3.90 \times 10^{-3} M^{0.82}$ was obtained here by the least squares analysis of the logarithmic plot between [ $\eta]$, in water, and $M$. The standard deviation of this plot was found to be $3.2 \times 10^{-5}$. The higher value of $v$ and the good linearity demonstrated by the standard deviation, obtained in the present study, indicate the validity of KMHS in a wider range of molar mass contradicting the phenomena observed by Scholtan. ${ }^{22}$ The very recent report

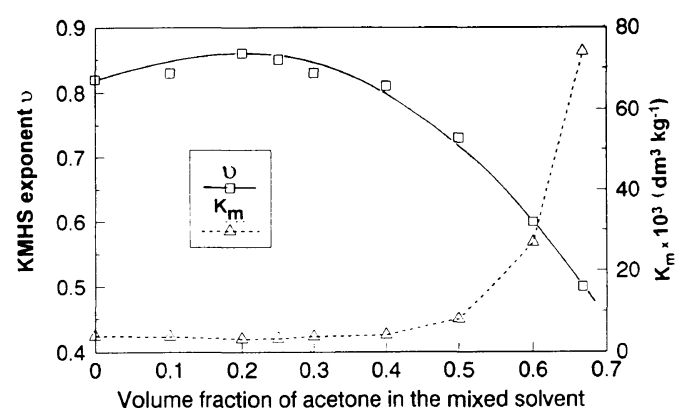

Figure 1. Variation of Kuhn-Mark-Houwink-Sakurada constants $K_{\mathrm{m}}$ and $v$ as a function of acetone volume fraction $\phi_{\mathrm{ACT}}$.

published by Ahmed et al. ${ }^{33}$ concluded no bending was observed and the logarithmic relationship between $[\eta]$ and $M$ in the entire range is linear. However, the molar mass range studied by these authors was $11.31 \times 10^{3}$ $76.49 \times 10^{3}$ and according to Scholtan ${ }^{22}$ the logarithmic relationship is linear in this range.

The addition of a second liquid to a binary liquid-polymer system to produce a ternary system is used widely for a variety of purposes. If the second liquid is a poor solvent, or a precipitant for the polymer, the dissolving potential of the liquid medium can be reduced and eventual phase separation may occur. This does not necessarily take place in every event and sometimes mixture of two relatively poor solvents can even produce an enhanced solvent power. ${ }^{12,34}$ The mixed solvent is then said to exhibit a synergistic effect, which is manifested as a maximum in the limiting viscosity number $[\eta]$ curve when measured as a function of the mixed solvent composition. ${ }^{35}$

In the present system the synergistic effect is represented as a maximum and minimum in the KMHS constant $v$ and $K_{\mathrm{m}}$ respectively, when they are plotted as a function of solvent composition ( $c f$., Figure 1). Our results run in harmony with the results given by Meza and Gargallo $^{25}$ for the ternary systems $\mathrm{PVP} / \mathrm{H}_{2} \mathrm{O} /$ acetone and $\mathrm{PVP} /$ chloroform/acetone. 
Unperturbed Dimensions (UD)

The UD are normally expressed in terms of $\left(\left\langle r^{2}\right\rangle_{0} / M\right)^{1 / 2}$ where $\left\langle r^{2}\right\rangle_{0}$ is the mean square end-to-end distance in the unperturbed state. Under $\theta$-conditions, $K_{\mathrm{m}}=K_{\theta}$ and, therefore

$$
K_{\theta}=\Phi_{0}\left(\left\langle r^{2}\right\rangle_{0} / M\right)^{3 / 2}
$$

where $\Phi_{0}$ is the universal Flory constant $\left(2.5 \times 10^{23} \mathrm{~mol}^{-1}\right) \cdot{ }^{36}$ In solvent $\mathrm{i}(\theta$-solvent) the value of $K_{\theta}$ (or equivalently that of the UD) is obtained directly from the KMHS plot. In the other solvents, indirect procedures were used to derive $K_{\theta}$.

The main procedures utilize various plots involving $[\eta]$ and $M$ and allow $K_{\theta}$ to be derived from the intercept. Five different extrapolation procedures, viz. those of Stockmayer and Fixman (S-F), ${ }^{32}$ Kurata and Stockmayer $(\mathrm{K}-\mathrm{S}),{ }^{37}$ Inagaki, Suzuki, and Kurata (I-S$\mathrm{K}),{ }^{38}$ Ueda and Kajitani (U-K), ${ }^{39}$ and Kamide and Moore $(\mathrm{K}-\mathrm{M})^{40}$ have been compared in the present investigation. The relevant plots yielded values of $K_{\theta}$ given in Table III.

The procedure of Kamide and Moore $(\mathrm{K}-\mathrm{M})^{40}$ differs from the others in the respect that its plot invokes values of $K_{\mathrm{m}}$ and $v$ for each of the solvents used. Consequently, only one value of $K_{\theta}$ is yielded. In this procedure, the simplified form of the original equation suggested by Abdel-Azim and $\mathrm{Huglin}^{3}$ was used.

One additional indirect procedure was used. Munk and Halbrook $(\mathrm{M}-\mathrm{H})^{41}$ have proposed equation 3 for calculating $K_{\theta}$

$$
K_{\theta}=Q^{3 /(4-2 v)}
$$

where

$$
Q=K_{\mathrm{m}}\left(\Phi_{0}{ }^{(1-2 v) / 3}\right)\left(N_{0}{ }^{1 / 2} M / L\right)^{2 v-1}
$$

These workers postulated that there is no thermodynamic interaction among macromolecular segments within a short section of chain with a characteristic number of segments $N_{0}$, estimated by them to be 9 for polystyrene. The contour length parameter $M / L$ of polystyrene was calculated ${ }^{41}$ to be $4.14 \times 10^{8}$
Table IIII. Values of $10^{3} \times K_{\theta}$ (in $\mathrm{dm}^{3} \mathrm{~kg}^{-1}$ ) derived from different extrapolation procedures for PVP in different mixed solvents at $298.15 \mathrm{~K}$

\begin{tabular}{ccccccc}
\hline & \multicolumn{5}{c}{ Procedure } \\
\cline { 2 - 7 } Solvent & S-F & U-K & K-S & I-S-K & K-M & A-S-F \\
\cline { 2 - 7 } & & & & & \\
a & 60 & 34 & 36 & 27 & 74 & 73 \\
b & 61 & 32 & 64 & 13 & 74 & 75 \\
c & 61 & 21 & 62 & 25 & 74 & 75 \\
d & 61 & 25 & 62 & 47 & 74 & 75 \\
e & 61 & 31 & 64 & 33 & 74 & 74 \\
f & 61 & 38 & 65 & 31 & 74 & 73 \\
g & 64 & 46 & 69 & 46 & 74 & 74 \\
h & 69 & 67 & 72 & 78 & 74 & 74 \\
i & 74 & 74 & 74 & 74 & 74 & 74 \\
\hline
\end{tabular}

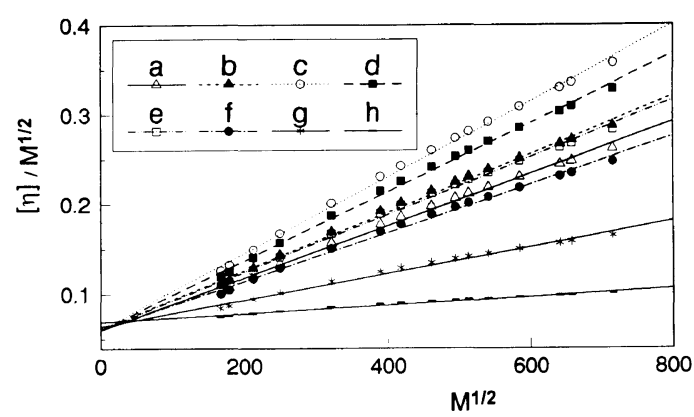

Figure 2. Stockmayer-Fixman plot for PVP samples in different solvents.

$\mathrm{kg} \mathrm{mol}^{-1} \mathrm{~m}^{-1}$. Abdel-Azim and Huglin ${ }^{3}$ have recast equation ${ }^{3}$ into the following form

$$
\log Q=[(4-2 v) / 3] \log K_{\theta}
$$

The value of $K_{\theta}$ is obtained from the slope of the plot $\log Q$ versus $(4-2 v) / 3$. For PVP we calculated the contour length parameter $M / L$. The value of $4.46 \times 10^{8} \mathrm{~kg} \mathrm{~mol}^{-1} \mathrm{~m}^{-1}$ was assigned for this parameter.

Graphs to all these methods afforded good linearity in general as manifested by the correlation coefficients of the least squares analysis of the data points. Stockmayer-Fixman plot [S-F] was selected, Figure 2, in view of the fact that it exhibited a behavior widely different from that previously observed in a study of another vinyl polymer system. ${ }^{3}$ In that 


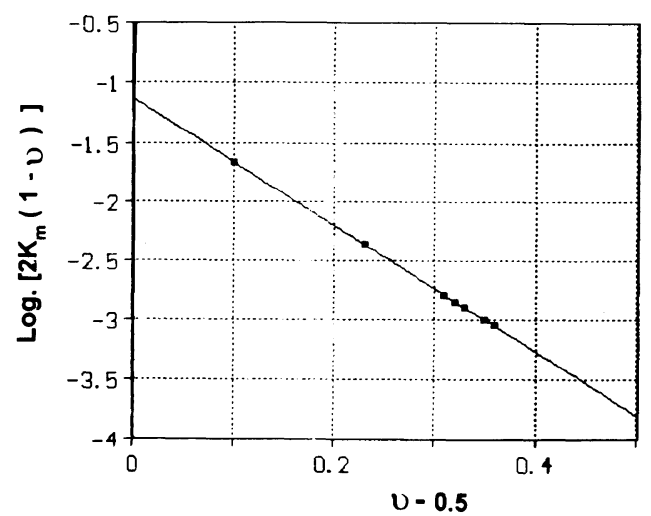

Figure 3. Plot according to the simplified form of Kamide and Moore procedure (K-M).

case, the downward deviation from linearity could be interpreted as being a result of solvent power. The deviation occurred when $M \geq 10^{6}$, but only for $v \geq 0.7$. However, in the present system the maximum power of the solvent mixture afforded $v=0.86$ while the highest molar mass was $512 \times 10^{3}$ and consequently this deviation, as expected, disappeared. The values of $K_{\theta}$ obtained by this procedure ( $c f$., Table III) vary from $60 \times 10^{-3}$ to $74 \times 10^{-3}$ $\mathrm{dm}^{-3} \mathrm{~kg}^{-1}$.

Of perhaps greater importance is the success of these procedures in yielding a unique intercept (and hence $K_{\theta}$ ) independent of the nature of the solvent medium. Table III shows that only the K-M method fulfills this directly, since it produces only one value for all solvents, and yields $K_{\theta}=74 \times 10^{-3} \mathrm{dm}^{-3} \mathrm{~kg}^{-1}$. The plot representing this procedure is shown in Figure 3 . In all other procedures the plots intersect before the ordinate axis as a consequence of which the intercepts, and hence $K_{\theta}$ values, increase with decreasing solvent power.

It can be seen from the results in Table III that S-F plot is apparently inadequate in its present form, being inflexible in non-ideal solvents while its validity increases near to theta conditions.

The following section represents our attempt to derive a unique value of $K_{\theta}$ from the intercepts obtained by S-F plots of PVP in different solvents with varying solvation power. It was found possible to obtain comparable values of $K_{\theta}$ from S-F plot in good and poor solvents by captivating the volume effect. Ptitsyn and Eizner ${ }^{42}$ have shown that the deviation from the law of proportionality of [ $\eta$ ] on $M^{1 / 2}$, according to Flory, is wholly explained by deviation from the law of proportionality of $\left\langle r^{2}\right\rangle$ on $M$ as connected with the volume effects. The authors found that

$$
\left\langle r^{2}\right\rangle \alpha M^{1+\varepsilon}
$$

where, $\varepsilon$ increases from 0 to 0.2 as the exponent $v$ in KMHS equation increases from 0.5 to 0.8 following the relationship

$$
\varepsilon=(2 v-1) / 3
$$

For the sake of obtaining a unique value of $K_{\theta}$ from $\mathrm{S}-\mathrm{F}$ plot, or minimizing the dependance of $K_{\theta}$ on KMHS exponent $v$, we considered that fact $^{42}$ that in highly active solvents the influence of volume effects on $[\eta]$ is accounted in terms of their influence on their $\left\langle r^{2}\right\rangle$. As the statistical radius, $\left\langle r^{2}\right\rangle$, increases more rapidly than $M$, a correction for this effect should be introduced in S-F equation. Consequently, to be able to handle the variable unperturbed dimensions, we eliminate the dependance of $K_{\theta}$ on KMHS exponent $v$ by calculating the value of $\varepsilon$ for each solvent, using eq 7. The $K_{\theta}$ value, derived from S-F plot, for each solvent was corrected by multiplying its value by $(1+\varepsilon)$. The corrected values are designated as A-S-F and listed in the last column of Table III. These values show not only that the parameter $(1+\varepsilon)$ is a solventdependent factor modifying $K_{\theta}$ derived from data in non-ideal solvents but also it still valid in theta solvents since the parameter $(1+\varepsilon)=1$ when $v=0.5 \quad[c f$. , eq 7]. An additional conclusion withdrawn from comparing the derived values of $K_{\theta}$ according to the new treatment, is the good agreement with the value of $K_{\theta}$ obtained by direct measurements under $\theta$-condition (solvent i). Values ranging between 
$73 \times 10^{-3}$ and $75 \times 10^{-3} \mathrm{dm}^{3} \mathrm{~kg}^{-1}$ were obtained. The mean value of $K_{\theta}$ obtained by this method was found to be $74 \times 10^{-3} \mathrm{dm}^{3} \mathrm{~kg}^{-1}$ which is exactly the same as the value measured at $\theta$-conditions and the value obtained by $\mathrm{K}-\mathrm{M}$ procedure.

With regard to the M-H method, the characteristic number of segments, $N_{0}=9$, afforded rather low values of $K_{\theta}$. Substituting $N_{0}=21$ in equation 4 yielded values of $K_{\theta}$ ranging between $65 \times 10^{-3}$ and $75 \times 10^{-3} \mathrm{dm}^{3} \mathrm{~kg}^{-1}$ with an average of $69 \times 10^{-3} \mathrm{dm}^{3} \mathrm{~kg}^{-1}$. The actual plot (not produced here) displayed some scatter, the value of $K_{\theta}$ via least-squares analysis being $68 \times 10^{-3} \mathrm{dm}^{3} \mathrm{~kg}^{-1}$, which is somewhat smaller than the average of the calculated values for each solvent individually $\left(=69 \times 10^{-3}\right)$.

As it was expected, the I-S-K procedure yielded widely discordant values of $K_{\theta}$ since the originators $^{38}$ of this procedure suggested its restriction to systems in which $\alpha>1.4$. Here the value of $\alpha$ exceeds 1.4 for PVP fractions PVP1-PVP5 when $v \geq 0.82$.

For the most reliable procedures, mentioned above, the value of $K_{\theta}$ for PVP was found to be $74 \times 10^{-3} \mathrm{dm}^{3} \mathrm{~kg}^{-1}$. From this value, the UD calculated from eq 2 using $\Phi_{0}=2.5 \times 10^{23}$ $\mathrm{mol}^{-132}$ was found to be $0.666 \AA \mathrm{g}^{-(1 / 2)}$ $\mathrm{mol}^{1 / 2}$. This value is subjected to an absolute error arising from the uncertainty in the value assigned to $\Phi_{0}$. Commonly adopted values of $\Phi_{0}$ are $2.5 \times 10^{23}$ and $2.87 \times 10^{23} \mathrm{~mol}^{-1}$. The latter value yields $\left(\left\langle r^{2}\right\rangle_{0} / M\right)^{1 / 2}$ equal to $0.636 \AA \mathrm{g}^{-(1 / 2)} \mathrm{mol}^{1 / 2}$. When the value of $\Phi_{0}$ is taken $^{43}$ as $2.71 \times 10^{23} \mathrm{~mol}^{-1}$ the UD is $0.649 \AA \mathrm{g}^{-(1 / 2)} \mathrm{mol}^{1 / 2}$. However, the value of $\left(\left\langle r^{2}\right\rangle_{0} / M\right)^{1 / 2}$ obtained by using different values of $\Phi_{0}$ was ranging between 0.636 and $0.666 \AA \mathrm{g}^{-(1 / 2)} \mathrm{mol}^{1 / 2}$. These values are comparable with the value of 0.77 given by Levy and Frank $^{44}$ at $303.15 \mathrm{~K}$ although they used a value of $2.1 \times 10^{23}$ for $\Phi_{0}$.

\section{CONCLUSIONS}

Extrapolation procedures were conceived originally as a convenient means of deriving UD from experimental data relating to a variety of conditions of solvent and different molar masses of polymer. As soon as the successful implementation of a particular method is found to be contingent on any restrictions, this method necessarily looses some of its attraction. Such is the situation with regard to certain of the procedures discussed above. For the solutions examined here, there is a wide range of thermodynamic solvent power, the minimum and maximum values of $\alpha$ being 1.00 and 1.69 , respectively.

Provided several liquids with widely varying solvent power are available, method $\mathrm{K}-\mathrm{M}$ is seen to be very reliable. If it is desired to use only non-ideal solvents, our correction for S-F plot is recommended when the extrapolated lines of S-F plot intersect before the ordinate axis. We believe that newly proposed correction factor leads (1) to $K_{\theta}$ values for all solvents confined to a narrow range, and (2) to obtain $K_{\theta}$ values very close to the directly determined value under $\theta$-condition (solvent $\mathrm{i}$ ). The procedure of U-K was successful in the zwitterionic polymethacrylate solutions studied recently by Huglin and Radwan ${ }^{45}$ but in the present system it showed widely scattered values of $K_{\theta}$, all considerably smaller than that obtained at the $\theta$-condition.

From the most reliable procedures mentioned above, the value of $K_{\theta}$ for PVP was found to be $74 \times 10^{-3} \mathrm{dm}^{3} \mathrm{~kg}^{-1}$. From this value of $K_{\theta}$ eq 2 yields a value of $0.666 \AA \mathrm{g}^{1 / 2}$ $\mathrm{mol}^{1 / 2}$ for the UD. This is a value of entirely reasonable magnitude and is similar to that for other vinyl polymers like polystyrene for which UD of $0.681 \AA \mathrm{g}^{1 / 2} \mathrm{~mol}^{1 / 2}$ was reported. ${ }^{4}$

Acknowledgment. One of us (A.A.A.) thanks the Department of Polymer Chemistry, University of Helsinki for the provision of a maintenance grant. 


\section{REFERENCES}

1. A.-A. A. Abdel-Azim and M. B. Huglin, Makromol. Chem. Rapid Commun., 2, 119 (1981).

2. A.-A. A. Abdel-Azim and M. B. Huglin, Makromol. Chem. Rapid Commun., 3, 437 (1982).

3. A.-A. A. Abdel-Azim and M. B. Huglin, Eur. Polym. J., 18, 735 (1982).

4. A.-A. A. Abdel-Azim and M. B. Huglin, Polymer, 24, 1429 (1983).

5. A.-A. A. Abdel-Azim and S. S. Samy, Polym. Commun., 29, 85 (1988).

6. A. Vrij, J. Polym. Sci., A-1, 7, 1627 (1969).

7. A. Dondos, Makromol. Chem., 135, 181 (1970).

8. A. Dondos, P. Rempp, and H. Benoit, J. Polym. Sci., $C$, 30, 9 (1970).

9. J. Scornaux and R. Van. Leemput, Makromol. Chem., 177, 2721 (1976).

10. A. Dondos, V. Havredaki, and A. Mitsou, Makromol. Chem., 176, 1481 (1975).

11. V. E. Eskin, T. Nekrasova, and U. Juraev, Eur. Polym. J., 11, 341 (1975).

12. A.-A. A. Abdel-Azim, S. S. Samy, M. M. El-Dessouky, F. Abdel-Rehim, and S. A. Hassan, Polymer, 27, 1046 (1986).

13. B. Celda, C. M. Gomez, R. Gavara, R. Tejero, and A. Campos, Makromol. Chem., 188, 2909 (1987).

14. R. Tejero, C. M. Gomez, B. Celda, R. Gavara, and A. Campos, Makromol. Chem., 189, 1643 (1988).

15. B. Celda, R. Gavara, C. M. Gomez, R. Tejero, and A. Campos, Makromol. Chem., 189, 1657 (1988).

16. A. Dondos and H. Benoit, Eur. Polym. J., 4, 561 (1968).

17. A. Dondos and D. Patterson, J. Polym. Sci., 27, 209 (1969).

18. J. L. Asorlosa and A. J. Martinelli, in "Water-soluble Resins," R. L. Davidson and M. Sitting, Ed., Chapman and Hall, New York, N.Y., 1962, p 110.

19. F. Haaf, A. Sanner, and F. Straub, Polym. J., 17, 143 (1985).

20. W. Linke and F. G. M. Vogler, Polym. News, 12, 232 (1987).

21. K. Dialer and K. Vogel, Makromol. Chem., 6, 191 (1951).
22. W. Scholtan, Makromol. Chem., 7, 209 (1952).

23. H. P. Frank and G. B. Levy, J. Polym. Sci., 10, 371 (1953).

24. L. E. Miller and F. A. Hamm, J. Phys. Chem., 57, 110 (1953).

25. R. Meza and L. Gargallo, Eur. Polym. J., 13, 235 (1977).

26. G. M. Pavlov, E. F. Panarin, E. V. Korneeva, C. V. Kurochkin, V. E. Baikov, and V. N. Ushakova, Makromol. Chem., 191, 2889 (1990).

27. B. J. Jirgenson, Polym. Sci., 8, 519 (1952).

28. M. L. Huggins, J. Am. Chem. Soc., 64, 2716 (1942).

29. E. O. Kraemer, Ind. Engng. Chem., 30, 1200 (1938).

30. H.-G. Elias, Makromol. Chem., 50, 1 (1961).

31. H.-G. Elias, Makromol. Chem., 54, 78 (1962).

32. W. H. Stockmayer and M. Fixman, J. Polym. Sci., C, 1, 137 (1963).

33. N. Ahmed, B. Ahmed, and A. Bhettani, J. Chem. Soc. Pak., 13(3), 153 (1991).

34. J. M. G. Cowie and J. T. McCrindle, Eur. Polym. J., 8, 1325 (1972).

35. P. Munk, M. T. Abjaoude, and M. E. Halbrook, $J$. Polym. Sci., Polym. Phys. Ed., 16, 105 (1978).

36. R. E. Bareiss, Makromol. Chem., Rapid Commun., 2, 523 (1981).

37. M. Kurata and W. H. Stockmayer, Fortschr. Hochpolym. Forsch., 3, 196 (1963).

38. H. Ingaki, H. Suzuki, and M. Kurata, J. Polym. Sci. C, 15, 409 (1966).

39. M. Ueda and K. Kajitani, Makromol. Chem., 108, 138 (1967).

40. K. Kamide and W. R. Moore, J. Polym. Sci., B, 2, 809 (1964).

41. P. Munk and M. E. Halbrook, Macromolecules, 9, 441 (1976)

42. O. B. Ptitsyn and Yu. E. Eizner, Soviet Phys. Tech. Phys (transl.), 4, 1020 (1960).

43. A.-A. A. Abded-Azim and M. B. Huglin, Polymer, 25, 803 (1984).

44. G. B. Levy and H. P. Frank, J. Polym. Sci., 17, 247 (1955).

45. M. B. Huglin and M. A. Radwan, Polym. International, 26, 97 (1991). 